\title{
POTENSI LAHAN UNTUK BUDIDAYA PISANG DI KECAMATAN JENAWI KARANGANYAR
}

\author{
Mujiyo $^{\left.1^{*}\right)}$, Hery Widijanto ${ }^{1)}$, Aktavia Herawati ${ }^{1)}$, Fatchur Rochman ${ }^{2)}$ dan Rizkisadi Rafirman ${ }^{1)}$ \\ ${ }^{1)}$ Program Studi Ilmu Tanah, Fakultas Pertanian, Universitas Sebelas Maret Surakarta \\ ${ }^{2)}$ Pengendali Organisme Pengganggu Tumbuhan Kecamatan Jenawi, Kabupaten Karanganyar
}

*Corresponding author: mujiyo@staff.uns.ac.id

\begin{abstract}
Banana (Musa spp.) is a tropical fruit that is widely grown in Indonesia as it beneficially increases the farmers' welfare. However, the wider scale of suitable land still needs to be developed. This study aims to know the distribution of suitable locations for banana cultivation in Jenawi based on the climate conditions. The research was done by making soil map unit, characterizing land's climate, matching climate conditions with plant growth requirements, and then mapping the suitable location for banana cultivation. The results showed that the agriculture's climate suitability in Jenawi is classified into two areas: (1) middle - upper/eastern area (not suitable for banana cultivation as it is located in the high area of 2,056 masl with the low temperature $13.8^{\circ} \mathrm{C}$ and the high rainfall 3,750 mm/year); (2) middle lower/west area (suitable for banana cultivation as it is located in the lower area of 610 masl with the higher temperature $22.6{ }^{\circ} \mathrm{C}$ and lower rainfall 3,333 mm/year. So that the banana plants are potentially developed in the middle - lower/west area of Jenawi i.e. in the Village of Trengguli, Sidomukti, Balong, Lempong, Menjing and Seloromo. The determination of the land suitability class in detail and in terms of the characteristics and quality of the soil can be more focused on the area which suitable climate conditions in order to obtain the land suitability class, limiting factors and improvement efforts.
\end{abstract}

Keywords: Agriculture's climate; Banana; Land suitability

Cite this as: Mujiyo, M., Widijanto, H., Herawati, A., Rochman, F., \& Rafirman, R. 2017. Potensi Lahan untuk Budidaya Pisang di Kecamatan Jenawi Karanganyar. Caraka Tani: Journal of Sustainable Agriculture. 32(2), 142148. doi: http://dx.doi.org/10.20961/carakatani.v32i2.17020

\section{PENDAHULUAN}

Pisang (Musa spp.) termasuk komoditas buahbuahan prioritas di Indonesia dengan produksi sebesar 7,3 juta ton pada tahun 2015 (Kementerian Pertanian, 2016). Tahun 2014 tanaman pisang juga menempati peringkat pertama untuk produksi buah dengan produksi mencapai 6,8 juta ton yang memberikan kontribusi terbesar terhadap produksi buah nasional (Direktorat Jenderal Hortikultura, 2015). Pisang adalah komoditas buah tropika yang dicanangkan oleh Kementerian Riset dan Teknologi untuk dikembangkan di Indonesia yang didasarkan dengan pertimbangan bahwa pisang merupakan komoditas berorientasi kerakyatan yang mampu meningkatkan kesejahteraan petani (Kasutjianingati dan Boer, 2013). Buah pisang merupakan buah yang sangat bermanfaat bagi kehidupan manusia, yang dapat dikonsumsi kapan saja dan pada segala tingkatan usia. Karbohidrat buah pisang merupakan karbohidrat kompleks tingkat sedang dan tersedia secara bertahap sehingga penyediaan energinya tidak terlalu cepat, sedikit lebih lambat dari pada gula pasir dan sirup, tetapi lebih cepat dari pada nasi, biskuit dan sejenis roti (Balitbang Pertanian, 2008). Vitamin $\mathrm{A}, \mathrm{B}$, dan $\mathrm{C}$ juga terdapat dalam buah pisang yang bermanfaat untuk membantu memperlancar sistem metabolisme tubuh dan meningkatkan daya tahan tubuh dari radikal bebas (Wijaya, 2013).

Salah satu aspek pengembangan komoditas pisang adalah bagaimana menyediakan lahan yang sesuai untuk skala pengembangan yang lebih luas. Tanaman pisang dapat digunakan sebagai tanaman konservasi pada daerah kering dan kritis. Tanaman pisang termasuk monokotil yang tumbuh baik di daerah tropika pada ketinggian $100-700 \mathrm{~m}$ dpl tetapi lebih cocok pada dataran rendah tropis basah, suhu udara $22-32{ }^{\circ} \mathrm{C}$ dan curah hujan $2.000-3.000 \mathrm{~mm} /$ tahun (Sunarjono, 
2002). Sementara itu menurut Ritung et al. (2011) tanaman pisang dapat tumbuh dengan baik pada daerah dengan suhu udara $25-27{ }^{\circ} \mathrm{C}$, kelembapan udara $>60 \%$, ketinggian tempat $<1.200 \mathrm{~m} \mathrm{dpl}$, curah hujan $1.500-2.500 \mathrm{~mm} /$ tahun dan lama bulan kering (curah hujan $<60 \mathrm{~mm} /$ bulan) $0-3$ bulan.

Luas Kecamatan Jenawi sekitar 5.608,28 ha dengan penggunaan tanah sawah 524,14 ha dan tanah kering 5.084,14 ha. Penggunaan tanah kering diantaranya untuk pekarangan dan bangunan 765,00 ha, tegalan/kebun 1.991,00 ha, hutan negara 1.600,67 ha, padang rumput 11,00 ha dan perkebunan 611,00 ha (BPS Karanganyar, 2017). Tanaman pisang dapat dikembangkan pada tanah kering seperti pekarangan, tegalan/kebun, hutan negara dan perkebunan. Luas tanah kering yang dominan di Kecamatan Jenawi merupakan lahan potensial yang dapat digunakan untuk pengembangan pisang.

Kecamatan Jenawi berdasarkan posisi geografis dan potensi lahan mempunyai prospek dan peluang yang baik untuk budidaya tanaman pisang. Oleh karena itu perlu dilakukan evaluasi kesesuaian lahannya sehingga dapat diketahui penyebaran lokasinya. Sebagai langkah awal dan utama adalah evaluasi kesesuaian lahan berdasarkan kondisi iklim untuk pertanian (agroklimat). Pembatasan ini bertujuan agar nantinya dalam penentuan kelas kesesuaian lahan secara lengkap dan detil dapat lebih difokuskan pada daerah yang secara agroklimat memungkinkan tanaman pisang dapat dibudidayakan dan tumbuh dengan baik.

\section{METODE PENELITIAN}

Penelitian ini merupakan explorative research dengan melalui pendekatan survei, yang didukung dengan analisis di laboratorium. Satuan analisis adalah satuan peta tanah (SPT). Setiap SPT dideskripsikan jenis tanah dan kondisi agroklimatnya, yang kemudian dilakukan pencocokan (matching) dengan persyaratan tumbuh tanaman pisang.

\section{Pembuatan dan Deskripsi Satuan Peta Tanah}

Satuan peta tanah (SPT) dibuat dengan survei metode transek. Pengambilan dan pengamatan sampel tanah pada setiap jarak $250 \mathrm{~m}$ mengikuti garis transek yang tegak lurus dengan arah kemiringan lereng atau garis kontur. Pengambilan dan pengamatan sampel tanah mengacu Petunjuk
Teknis Pengamatan Tanah oleh Balitanah (Hidayat et al., 2004) dan Guidelines for Soil Description (FAO, 2006). Pembatasan SPT dengan mengelompokkan titik-titik yang mempunyai keseragaman karakteristik tanah. Deskripsi SPT dengan melakukan penyidikan profil tanah pewakil. Profil dibuat dengan ukuran lebar $1,5 \mathrm{~m}$, panjang $2 \mathrm{~m}$ dan kedalaman $1,5 \mathrm{~m}$. Pencandraan jenis tanah mengikuti prosedur Soil Taxonomy USDA (Soil Survey Staff, 2014). Analisis sifat tanah di lapangan mengikuti Poerwowidodo (1992). Analisis tanah di laboratorium mengikuti prosedur oleh Mueller et al. (1992), Eviati dan Sulaeman (2009) dan Santoso dan Widati (2007). Pemetaan menggunakan software ArcView GIS 3.3 mengacu prosedur oleh ESRI (2000) dan Prahasta (2004).

\section{Karakterisasi Kondisi Agroklimat}

Kondisi agroklimat yang diamati adalah curah hujan dan suhu/temperatur udara. Rata-rata curah hujan tahunan diperoleh dari peta sebaran curah hujan Kecamatan Jenawi oleh Puslittanak (1994). Suhu udara diperoleh dengan cara menghitung yang menggunakan persamaan rumus Braak yaitu $\mathrm{T}=26,3{ }^{\circ} \mathrm{C}-\left(0,01 \times \mathrm{h} \times 0,6^{\circ} \mathrm{C}\right)$, di mana h adalah tinggi tempat yang akan dihitung suhu udaranya (Ritung et al., 2011). Tinggi tempat pada setiap SPT diperoleh dari rata-rata garis kontur pada peta topografi yang dibuat oleh Bakosurtanal (2010).

\section{Analisis Data}

Kelas kesesuaian agroklimat ditentukan dengan mencocokkan atau matching antara karakteristik agroklimat curah hujan dan suhu udara serta ketinggian tempat dengan persyaratan tumbuh tanaman pisang. Penentuan kelas kesesuaian lahan mengikuti prosedur oleh Ritung et al. (2011). SPT dikelompokkan menjadi 2 (dua) berdasarkan kelas kesesuaian lahannya yaitu kelompok sesuai (sesuai, cukup sesuai dan sesuai marginal) dan kelompok tidak sesuai.

\section{HASIL DAN PEMBAHASAN}

\section{Kondisi Lingkungan dan Agroklimat}

Kecamatan Jenawi adalah salah satu kecamatan di Kabupaten Karanganyar yang mempunyai luas 5.608 ha atau $7 \%$ dari luas Kabupaten Karanganyar (BPS Karanganyar, 2017). Secara geografis Kecamatan Jenawi terletak pada koordinat $111^{\circ} 4^{\prime} 54,063$ - 
$111^{\circ} 11^{\prime} 40,01 \mathrm{BT}$ dan $7^{\circ} 37^{\prime} 14,103-7^{\circ} 31^{\prime} 39,311$ LS. Wilayah ini terletak pada lereng barat Gunung Lawu dengan topografi wilayah berbukit hingga bergunung dan terbentuk secara dominan dari 3 formasi geologi volkan yaitu Qvl, Qlla, dan Qvjb. Formasi volkan Batuan Gunung Api Lawu (Qvl) terdiri dari tuf dan breksi gunungapi, formasi volkan Lahar Lawu (Qlla) terdiri dari komponen andesit dan basal, dan formasi volkan Breksi Jobolarangan (Qvjb) yang terdiri dari breksi gunung api yang bersisipan lava (Sampurna dan Samodra, 1997).

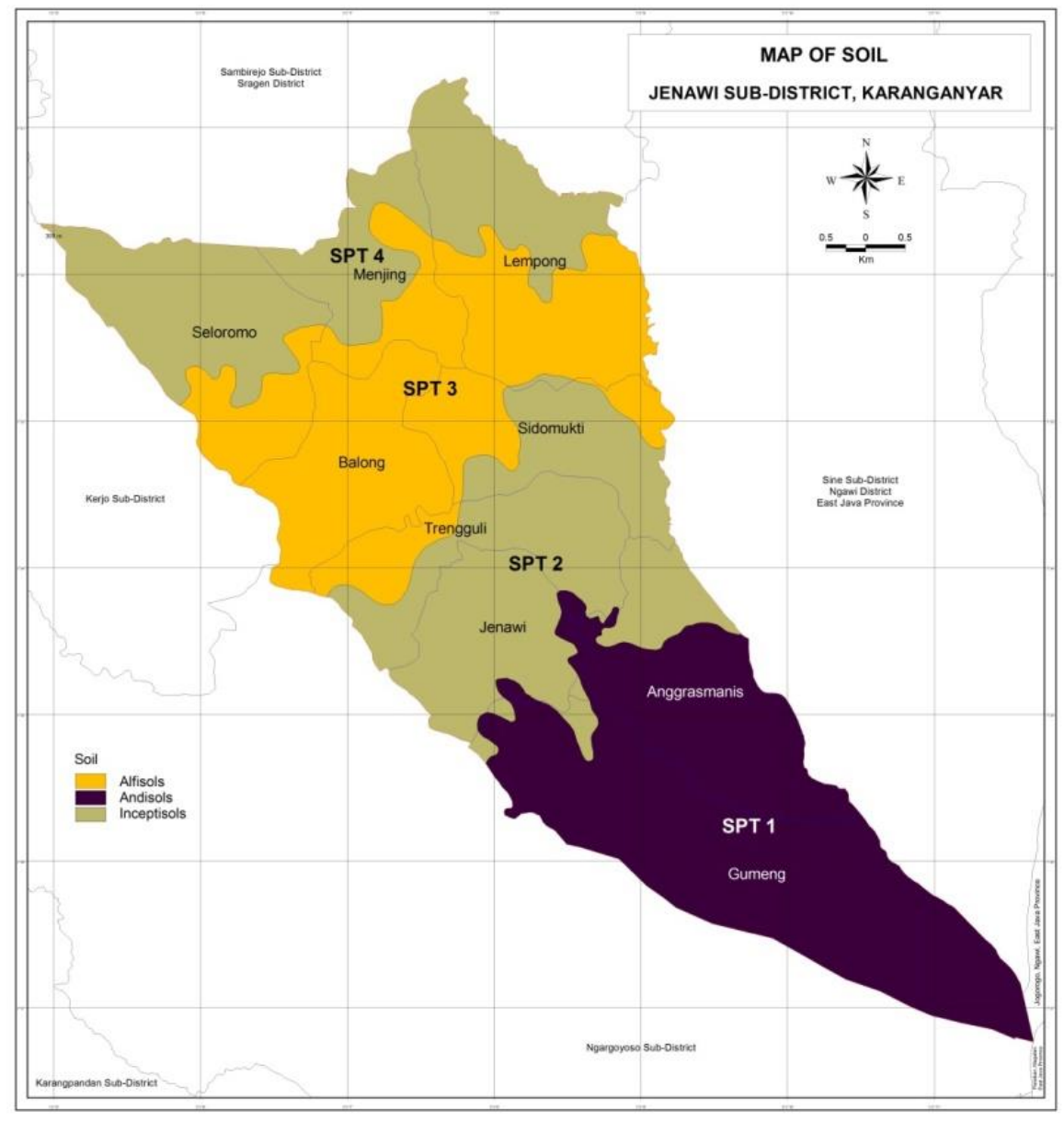

Gambar 1. Satuan Peta Tanah di Kecamatan Jenawi

Satuan peta tanah (SPT) 1 merupakan tanah Andisols, SPT 2 dan 4 Inceptisols dan SPT 3 Alfisols (Gambar 1). Tanah Andisols merupakan tanah khas daerah gunung api yang berbahan induk abu vulkan. Tanah ini mempunyai sifat penciri kandungan bahan organik tinggi $>2 \%$, warna gelap, berat volume rendah $<0,9 \mathrm{gr} / \mathrm{cm}^{3}$, retensi fosfat tinggi $>85 \%$ dan menunjukkan sifat smeary (lumur seperti minyak) apabila dipirid di antara dua jari. Tanah Inceptisols merupakan tanah yang relatif masih muda, tidak karena bahan induk yang baru saja melapuk, tetapi karena kondisi topografi miring yang menyebabkan proses pembentukan tanah lebih lambat. Tanah ini dicirikan oleh horison B (horison bawah, endopedon) cambic yaitu horison yang mulai berkembang ditunjukkan dengan salah satunya struktur tanah yang lebih mantap dari pada horison di atasnya. Tanah Alfisols merupakan tanah yang termasuk sudah berkembang dengan dicirikan oleh horison B (horison bawah, endopedon) argilic merupakan akumulasi klei (clay) dari horison di atasnya, kejenuhan basa tinggi $>35 \%$ dan $\mathrm{pH}>5,5$.

Kondisi agroklimat di Kecamatan Jenawi dibagi berdasarkan suhu udara dan curah hujan. Perbedaan tinggi tempat di Kecamatan Jenawi menyebabkan perbedaan karakteristik agroklimat di setiap SPT. SPT 1, 2, 3 dan 4 berturut-turut berada pada ketinggian rata-rata 2.056, 837, 593 dan $399 \mathrm{~m}$ dpl mempunyai temperatur rata-rata $14,0,21,3,22,7$ dan $23,9{ }^{\circ} \mathrm{C}$ dengan curah hujan 
rata-rata 3.750, 3.750, 3.250 dan $3.000 \mathrm{~mm} /$ tahun. Keberhasilan budidaya tanaman pisang tidak hanya ditentukan oleh tingkat kesuburan tanah dan teknik budidayanya saja, karena iklim sangat berpengaruh besar terhadap pertumbuhan tanaman pisang (Salau et al., 2016). Kekeringan, suhu tinggi atau rendah dan kelembapan tinggi mengakibatkan hasil pertanian menurun secara kuantitas dan kualitas (BPTP Maluku, 2017). Kelembapan tinggi akan memacu pertumbuhan jamur Fusarium, merupakan salah satu penyebab penyakit paling penting dan merusak pada pisang, tanaman mengalami layu dan kemudian mati (Gang et al., 2013; Ploetz, 2015). Namun demikian suhu rendah dan kelembapan tinggi berpengaruh baik terhadap daya simpan dan kualitas buah pisang (Ahmad et al., 2006).

\section{Kelas Kesesuaian Lahan untuk Tanaman Pisang}

Hasil matching menunjukkan bahwa kelas kesesuaian lahan untuk tanaman pisang di Kecamatan Jenawi adalah S2 (cukup sesuai), S3 (sesuai marginal) dan $\mathrm{N}$ (tidak sesuai) (Tabel 1). Kelas kesesuaian lahan SPT 1 dengan ketinggian tempat rata-rata $2.056 \mathrm{~m} \mathrm{dpl}$, temperatur udara $13,8{ }^{\circ} \mathrm{C}$ dan curah hujan $3.750 \mathrm{~mm} /$ tahun tidak sesuai untuk pertumbuhan pisang. Kelas kesesuaian lahan SPT 2 dan 3 dengan ketinggian tempat rata-rata 837 dan $593 \mathrm{~m}$ dpl temperatur udara 21,3 dan $22,7{ }^{\circ} \mathrm{C}$ dan curah hujan 3.750 dan $3.250 \mathrm{~mm} /$ tahun sesuai marginal untuk pertumbuhan pisang. Kelas kesesuaian lahan SPT 4 dengan ketinggian tempat rata-rata $399 \mathrm{~m} \mathrm{dpl}$, temperatur udara $23,9{ }^{\circ} \mathrm{C}$ dan curah hujan 3.000 $\mathrm{mm} / \mathrm{tahun}$ cukup sesuai untuk pertumbuhan pisang.

Tabel 1. Hasil Pencocokan/Matching antara Karakteristik Agroklimat dan Peryaratan Tumbuh Tanaman Pisang

\begin{tabular}{|c|c|c|c|c|c|c|c|c|c|}
\hline \multirow{2}{*}{$\begin{array}{c}\text { Karakteristik } \\
\text { Agroklimat } \\
\end{array}$} & \multirow{2}{*}{$\begin{array}{l}\text { Persyaratan } \\
\text { Tumbuh }\end{array}$} & \multicolumn{2}{|c|}{ SPT 1 } & \multicolumn{2}{|c|}{ SPT 2} & \multicolumn{2}{|c|}{ SPT 3} & \multicolumn{2}{|c|}{ SPT 4} \\
\hline & & Nilai & Kelas & Nilai & Kelas & Nilai & Kelas & Nilai & Kelas \\
\hline \multicolumn{10}{|l|}{ Temperatur/suhu (tc) } \\
\hline \multirow{4}{*}{$\begin{array}{l}\text { Temperatur rata-rata } \\
\left({ }^{\circ} \mathrm{C}\right)\end{array}$} & S1 : $25-27$ & & & & & & & & \\
\hline & S2 : 27-30 atau $22-25$ & & & & & 22,7 & S2 & 23,9 & S2 \\
\hline & S3 : $30-35$ atau $18-22$ & & & 21,3 & S3 & & & & \\
\hline & $\mathrm{N}:>35$ atau $<18$ & 13,8 & $\mathbf{N}$ & & & & & & \\
\hline \multirow{4}{*}{$\begin{array}{l}\text { Ketinggian Tempat } \\
\text { (mdpl) }\end{array}$} & S1 : $<1.200$ & & & 837 & S1 & 593 & S1 & 399 & S1 \\
\hline & $\mathrm{S} 2: 1.200-1.500$ & & & & & & & & \\
\hline & S3 : $1.500-2.000$ & & & & & & & & \\
\hline & $\mathrm{N}:>2.000$ & 2.056 & $\mathbf{N}$ & & & & & & \\
\hline \multicolumn{10}{|l|}{$\begin{array}{l}\text { Ketersediaan air (wa) } \\
\text { Curah hujan (mm/tahu }\end{array}$} \\
\hline & S2 $: 1.250-1.500$ atau $2.500-3.000$ & & & & & & & 3.000 & S2 \\
\hline & S3 $: 1.000-1.250$ atau $3.000-4.000$ & 3.750 & S3 & 3.750 & S3 & 3.250 & S3 & & \\
\hline & $\mathrm{N}:<1.000$ & & & & & & & & \\
\hline \multirow{2}{*}{\multicolumn{2}{|c|}{$\begin{array}{l}\text { Kelas } \\
\text { Sub-Kelas } \\
\end{array}$}} & \multirow{2}{*}{\multicolumn{2}{|c|}{$\begin{array}{c}\mathrm{N} \\
\mathrm{N}-\mathrm{tc}\end{array}$}} & \multirow{2}{*}{\multicolumn{2}{|c|}{$\begin{array}{c}\text { S3 } \\
\text { S3-tc.wa }\end{array}$}} & \multirow{2}{*}{\multicolumn{2}{|c|}{$\begin{array}{c}\text { S3 } \\
\text { S3-wa } \\
\end{array}$}} & \multirow{2}{*}{\multicolumn{2}{|c|}{$\begin{array}{c}\text { S3 } \\
\text { S2-tc,wa } \\
\end{array}$}} \\
\hline & & & & & c,wa & & & & \\
\hline
\end{tabular}

Keterangan: Persyaratan tumbuh tanaman pisang mengacu Ritung, et al. (2011)

$\mathrm{S} 1$ = sesuai, $\mathrm{S} 2$ = cukup sesuai, $\mathrm{S} 3$ = sesuai marginal, dan $\mathrm{N}$ = tidak sesuai

Aspek konservasi lahan juga harus mendapat perhatian, bagaimana dampak penggunaan lahan untuk budidaya pisang terhadap ancaman bahaya erosi tanah (Ritung et al., 2011). Hasil tumpangsusun (overlay) peta SPT dan kemiringan lereng menunjukkan bahwa SPT 1 didominasi oleh $71,21 \%$ luas wilayah mempunyai kemiringan lereng $40 \%$ dengan bahaya erosi berat - sangat berat (N). SPT 2 didominasi oleh 78,77\% luas wilayah mempunyai kemiringan lereng $15 \%$ dengan bahaya erosi sedang - berat (S3). SPT 3 dan 4 didominasi oleh masing-masing 85,27\% dan $85,37 \%$ luas wilayah mempunyai kemiringan lereng $0-15 \%$ dengan bahaya erosi sangat ringan - sedang (S2). Oleh karena itu dari segi konservasi lahan tanaman pisang layak 
dikembangkan di daerah tengah - bawah (barat) yaitu SPT 2, 3 dan 4, sementara itu di daerah tengah - atas (timur) yaitu SPT 1 tidak layak.

Secara umum kesesuaian lahan S2 mempunyai faktor pembatas yang memerlukan tambahan masukan (input) agar produktivitasnya dapat menyamai pada lahan yang sesuai (S1). Pembatas tersebut umumnya masih dapat diatasi oleh petani. Kesesuaian lahan S3 mempunyai faktor pembatas berat yang mempengaruhi produktivitasnya, memerlukan tambahan masukan yang lebih banyak dari pada lahan S2. Faktor pembatas pada S3 dapat diatasi dengan memerlukan modal tinggi yang petani tidak mampu mengatasinya, sehingga perlu bantuan dan intervensi pemerintah dan atau pihak swasta. Lahan $\mathrm{N}$ tidak sesuai karena mempunyai faktor pembatas yang sangat berat dan atau sulit diatasi. (Ritung et al., 2011).
Curah hujan rata-rata di daerah tengah - bawah (barat) yaitu SPT 2, 3 dan 4 sebesar 3.333 $\mathrm{mm} / \mathrm{tahun}$, sementara itu di daerah tengah - atas (timur) yaitu SPT 1 lebih tinggi sebesar 3.750 $\mathrm{mm} / \mathrm{tahun}$. Curah hujan yang berlebihan sangat mempengaruhi tingkat produktivitas pisang (Opeyemi et al., 2016). Tanaman pisang sangat rentan terhadap kondisi tanah yang jenuh air atau tergenang, sehingga harus dicegah dengan pengelolaan drainase yang baik (Ramirez et al., 2011). Kebutuhan air yang optimum untuk tanaman pisang berkisar antara $1.300-2.600$ $\mathrm{mm} / \mathrm{tahun}$, kadar air dalam tanah yang mencukupi atau pengelolaan irigasi yang baik dapat memberikan efek yang menguntungkan pada tanaman pisang seperti percepatan pematangan buah, meningkatkan hasil panen, bobot buah yang lebih besar, dan peningkatan jumlah buah per tandan (Stover, 1972; Sastry, 1988).

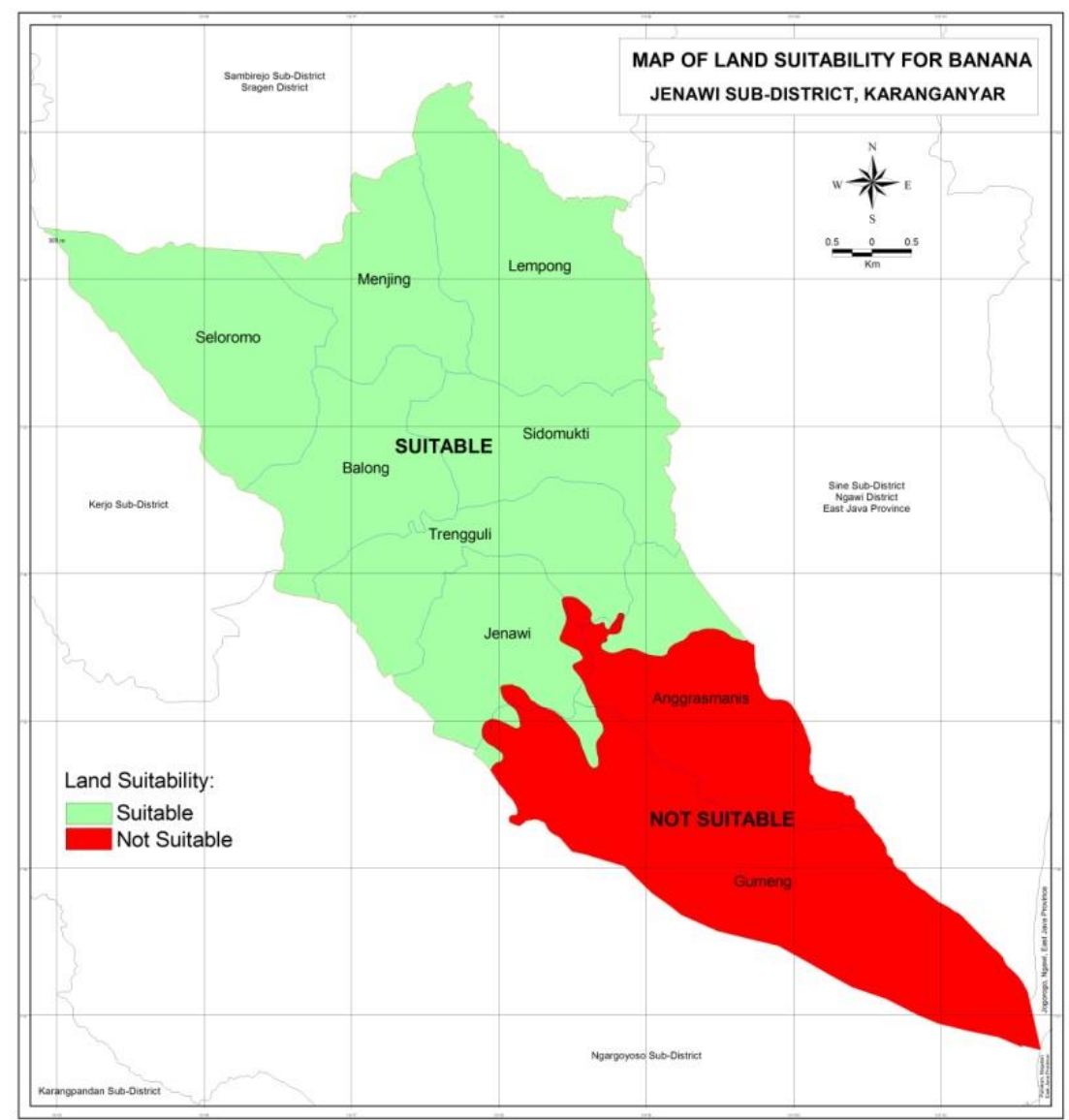

Gambar 2. Peta Kesesuaian Lahan untuk Pisang di Kecamatan Jenawi

Rata-rata ketinggian tempat dan suhu udara di daerah tengah - bawah (barat) yaitu SPT 2, 3 dan 4 sebesar $610 \mathrm{~m}$ dpl dan $22,6^{\circ} \mathrm{C}$, sementara itu di daerah tengah - atas (timur) yaitu SPT 1 ketinggian tempat lebih tinggi sebesar $2.056 \mathrm{~m} \mathrm{dpl}$ dan suhu udara lebih rendah sebesar $13,8{ }^{\circ} \mathrm{C}$. Faktor ketinggian tempat dan suhu udara merupakan faktor pembatas dalam budidaya 
pisang, merupakan faktor alam atau lingkungan yang sulit atau tidak bisa dimodifikasi. Ketinggian tempat berdampak pada suhu udara, curah hujan, kelembapan dan intensitas matahari. Suhu sangat berpengaruh terhadap pertumbuhan dan perkembangan tanaman pisang. Sastry (1988) mengungkapkan bahwa tanaman pisang yang tumbuh pada suhu di bawah $15,5{ }^{\circ} \mathrm{C}$ menyebabkan perkembangan daun pisang terhambat dan pematangan buah terlambat (Stover dan Simmonds, 1987).

Salah satu cara untuk mengatasi permasalahan suhu udara tersebut dengan memfokuskan penanaman pisang pada daerah dengan ketinggian yang lebih rendah dan suhu yang lebih tinggi yaitu pada SPT 2, 3 dan 4. Oleh karena itu penentuan kelas kesesuaian lahan secara lengkap dan detil nantinya dapat lebih difokuskan pada daerah yang secara agroklimat memungkinkan tanaman pisang dapat tumbuh dengan baik seperti di Desa Jenawi, Trengguli, Sidomukti, Balong, Lempong, Menjing dan Seloromo.

\section{KESIMPULAN}

Lahan di Kecamatan Jenawi daerah bagian tengah - atas (timur) tidak sesuai untuk tanaman pisang karena berada pada daerah tinggi rata-rata $2.056 \mathrm{~m}$ dpl, suhu udara rendah rata-rata $13,8{ }^{\circ} \mathrm{C}$ dan curah hujan tinggi rata-rata $3.750 \mathrm{~mm} /$ tahun. Lahan di daerah ini juga mempunyai ancaman bahaya erosi berat - sangat berat apabila digunakan untuk budidaya pisang. Lahan di daerah tengah - bawah (barat) sesuai untuk tanaman pisang karena berada pada daerah lebih rendah rata-rata $610 \mathrm{~m} \mathrm{dpl}$, suhu udara lebih tinggi rata-rata $22,6{ }^{\circ} \mathrm{C}$ dan curah hujan lebih rendah rata-rata $3.333 \mathrm{~mm} /$ tahun, sehingga komoditas pisang layak dan berpotensi untuk dikembangkan di daerah ini. Lahan-lahan tersebut mempunyai ancaman bahaya erosi sangat ringan, ringan, sedang dan berat apabila digunakan untuk budidaya pisang. Ancaman bahaya erosi sedang berat masih dapat diatasi dengan upaya-upaya konservasi lahan. Evaluasi kesesuaian lahan secara lengkap dan detil dari segi karakteristik dan kualitas tanah nantinya dapat lebih difokuskan pada daerah tersebut untuk memperoleh kelas kesesuaian lahan, faktor penghambat dan upaya perbaikannya. Kelas kesesuaian lahan yang cukup sesuai (S2) dan sesuai marginal (S3) dapat diupayakan perbaikannya oleh petani dengan bantuan dari berbagai pihak baik oleh pemerintah maupun swasta.

\section{ACKNOWLEDGEMENT}

Penulis mengucapkan terimakasih kepada Rektor UNS dan Ketua LPPM UNS yang telah mendanai kegiatan ini melalui skim hibah Penelitian Unggulan (PU-UNS) sumber dana PNBP UNS 2017.

\section{DAFTAR PUSTAKA}

Ahmad, H.U., Anwar, R., \& Thompson, A.K. 2006. Effect of High Humidity and Water on Storage Life and Quality of Bananas. International Journal of Agriculture \& Biology. 8(6), 828-831.

Bakosurtanal. 2010. Peta Rupa Bumi Indonesia. Badan Koordinasi Survei Tanah Nasional. Jakarta: Indonesia.

Balitbang Pertanian. 2007. Prospek dan Arah Pengembangan. Agribisnis Pisang. Edisi Kedua. Badan Penelitian dan Pengembangan Pertanian. Jakarta: Departemen Pertanian.

BPS Kabupaten Karanganyar. 2017. Karanganyar dalam Angka 2017. Badan Pusat Statistik Kabupaten Karanganyar.

BPTP Maluku. 2017. Pengaruh Iklim terhadap Pertanian.

Online: http://maluku.litbang.pertanian.go.id/index.ph p/berita/516-pengaruh-iklim-terhadappertanian.

Direktorat Jendral Hortikultura. 2015. Statistik Produksi Hortikultura Tahun 2014. Direktorat Jendral Hortikultura, Kementrian Pertanian. Jakarta: Indonesia.

ESRI. 2000. ArcView 3.3 Desktop Help. Environmental Systems Research Institute, Inc.

Eviati, \& Sulaeman. 2009. Petunjuk Teknis Edisi 2: Analisis Kimia Tanah, Tanaman, Air, dan Pupuk. Balai Penelitian Tanah. Balai Besar Litbang Sumber Daya Lahan Pertanian. Badan Penelitian dan Pengembangan Pertanian. Departemen Pertanian. Bogor.

FAO. 2006. Guidelines for Soil Description. $4^{\text {th }}$ Edition. Rome: Food and Agriculture Organization of the United Nations. 97p. 
Gang, G., Bizun, W., Weihong, M., Xiaofen, L., Xiaolin, Y., Chaohua, Z., Jianhong, M., \& Huicai, Z. 2013. Biocontrol of Fusarium wilt of banana: Key influence factors and strategies. African Journal of Micribiology Research. 7(41), 4835-4843.

Hidayat, A., Djaenudin, D., Suhardjo, H., \& Subardja, D. 2004. Petunjuk teknis pengamatan tanah. Balai Penelitian Tanah. Balai Besar Litbang Sumber Daya Lahan Pertanian. Badan Penelitian dan Pengembangan Pertanian. Departemen Pertanian. Bogor.

Kasutjianingati, \& Boer, D. 2013. Mikropropagasi Pisang Mas Kirana (Musa acuminata L) memanfaatkan BAP dan NAA secara In Vitro. J Agroteknos. 3(1), 60-64. ISSN: 2087-7706.

Kementerian Pertanian. 2016. Outlook Komoditas Pertanian Sub Sektor Hortikultura Pisang. Pusat Data dan Sistem Informasi Pertanian Kementerian Pertanian. Jakarta.

Mueller, T., Joergensen, R.G., \& Meyer, B. 1992. Estimation of soil microbial biomass $\mathrm{C}$ in the presence of fresh roots by fumigation extraction. Soil Biol. Biochem. 24,179-181.

Opeyemi, R.S., Mavelous, M., Oluwatosin, A.O., \& Rufus, S.O. 2016. Effects of Changes in Temperature, Rainfall and Relative Humidity on Banana Production in Ondo State, Nigeria. World Scientific News. 44, 143-154.

Ploetz, R.C. 2015. Fusarium Wilt of Banana. Phytopathology. 105(12), 1512-1521.

Poerwowidodo. 1992. Metode Selidik Tanah. Cetakan I. Edisi 1992. Surabaya: Penerbit Usaha Nasional.

Prahasta, E. 2004. Sistem Informasi Geografi: Tutorial Arcview. Bandung: Penerbit Informatika.

Puslittanak. 1994. Peta Jenis Tanah dan Agroklimat. Pusat Penelitian Tanah dan Agroklimat (Puslittanak). Departemen Pertanian Republik Indonesia. Bogor.

Ramirez, J., Jarvis, A., Bergh, I.V.D., Staver C., \& Turner D. 2011. Chapter 20, Changing Climates: Effects on Growing Conditions for Banana and Plantain (Musa spp.) and Possible Responses. Wiley and Sons.

Ritung, S., K. Nugroho, Mulyani A., \& Suryani E. 2011. Petunjuk Teknis Evaluasi Lahan untuk
Komoditas Pertanian (Edisi Revisi). Balai Besar Penelitian dan Pengembangan Sumberdaya Lahan Pertanian, Badan Penelitian dan Pengembangan Pertanian, Bogor.

Salau, O.R., Momoh, M., Olaleye, O.A., \& Owoeye. 2016. Effects of Changes in Temperature, Rainfall and Relative Humidity on Banana Production in Ondo State, Nigeria. World Scientific News. WSN. 44, 143-154.

Sampurna, \& Samodra. 1997. Peta Geologi Lembar Ponorogo, Jawa. Pusat Penelitian dan Pengembangan Geologi. Bandung.

Santoso, E., \& Widati, S. 2007. Analisis Biologi Tanah. Balai Penelitian Tanah. Balai Besar Litbang Sumber Daya Lahan Pertanian. Badan Penelitian dan Pengembangan Pertanian. Departemen Pertanian. Bogor.

Sastry, P.S.N. 1988. Agrometeorology of the Banana Crop. World Meterological Organization. Geneva.

Soil Survey Staff. 2014. Keys to soil taxonomy, 12 th ed. Washington, DC: USDA-Natural Resources Conservation Service,. 360p.

Stover, R.H. 1972. Banana, Plantain and Abaca Diseases. Commonwealth Mycological Institute. London. 316p.

Stover, R.H., \& Simmonds, N.W. 1987. Bananas. 3rd ed. Longman Scientific and Technical. Harlow.

Sunarjono, H. 2002. Budidaya Pisang dengan Bibit Kultur Jaringan. Jakarta: Penebar Swadaya.

Wijaya. 2013. Manfaat Buah Asli Indonesia. Jakarta: PT Gramedia. 